\section{NEW FACILITY OPENED IN LIVERPOOL}

Health Secretary Andy Burnham recently visited the Royal Liverpool and Broadgreen University Hospitals NHS Trust to officially open the Dental Hospital's new facility.

The Dental Hospital has recently received an investment of $£ 6$ million to improve dental education and services and the facility now has a new minor oral surgery area and dedicated facilities for patients with special needs and those who are medically compromised. This includes special wheelchair facilities and specially designed sedation suites.

The upper three floors include laboratories that are capable of supporting world class research into the prevention and treatment of dental diseases. These integrated facilities should enable scientific developments at Liverpool to impact directly on teaching and patient care.

The Health Secretary said, 'The investment in patient services means the Trust now boasts excellent dental care for

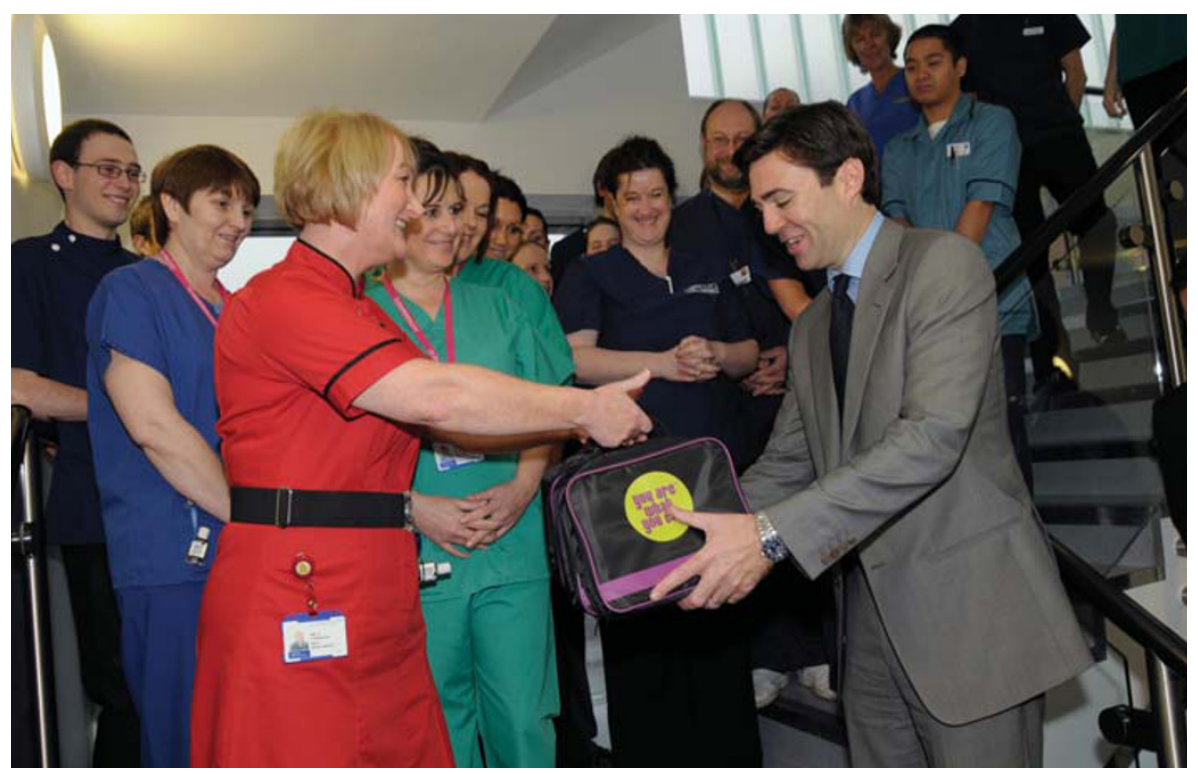

patients with special needs as well as top class educational facilities for the dentists of the future.'

Professor Sir Howard Newby, ViceChancellor of the University of Liverpool, said, 'The hospital has made significant contributions to health, research and education for more than 100 years and today is home to one of Europe's largest facilities for training dentists. This new development will help build on its pioneering history and bring researchers and clinicians together for the benefit of patient care.'

The Dental Hospital provides a range of specialist services for the local community including minor oral surgery, restorative dentistry, paediatric dentistry, orthodontics, oral surgery, oral medicine and special care dentistry.

\section{GROUP CELEBRATE SUCCESS}

A group of dentists from Newcastle Dental School are celebrating a string of awards and successes. Rhiannon Davies was awarded the British Society for Dental Research (BSDR) Junior Colgate Prize for her research Do patients with

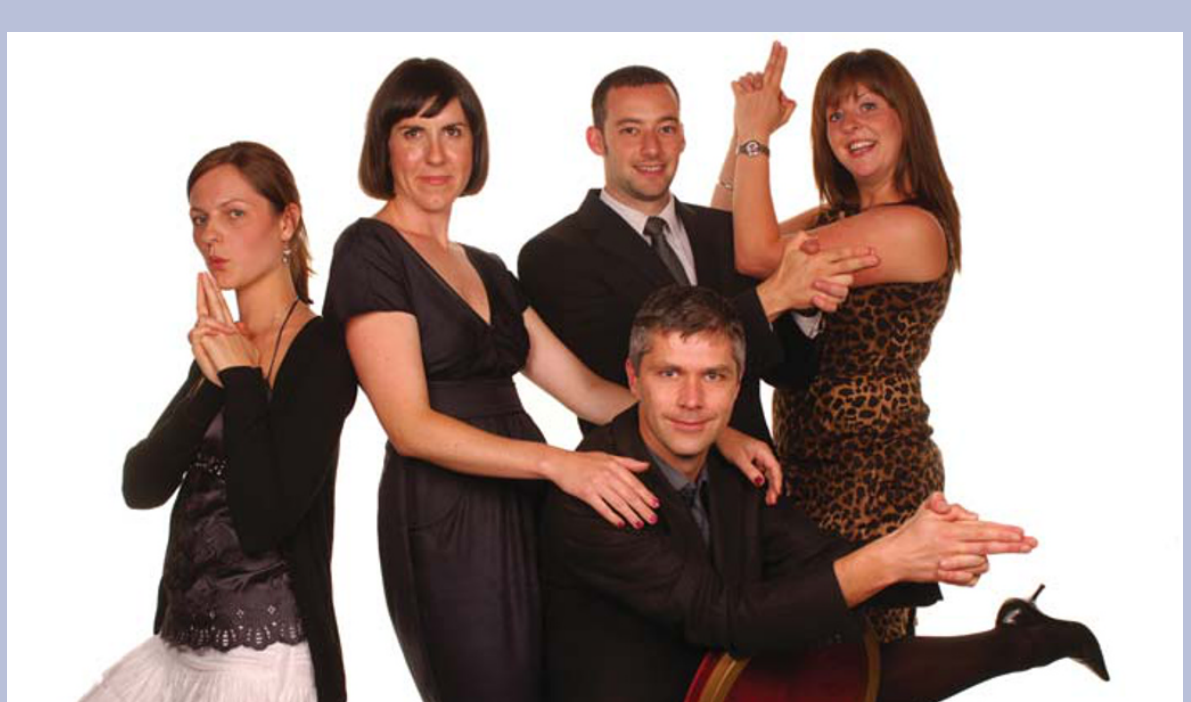

Licenced to Thrill are (I-r) Rhiannon Davies, Rebecca Wassall, James Field, Professor Philip Preshaw (seated) and Claire Storey aggressive periodontitis have subclinical diabetes?, which was completed as part of an intercalating Masters in Research degree. Rhiannon will now represent the BSDR in the Junior Hatton Prize competition at the International Asso- ciation for Dental Research Conference in Barcelona in 2010.

Rebecca Wassall, Clinical Fellow, has completed her PhD research project entitled Cytokine analysis in periodontitis patients with diabetes at Newcastle Dental School and James Field, a Clinical Fellow at Newcastle, is a winner of Oral and Dental Research Trust funding for his research 'Investigation into the erosive effects of fruit smoothies'.

Philip Preshaw (seated) has recently been promoted to Professor of Periodontology at Newcastle University, and has received a Distinguished Scientist Award from the International Association for Dental Research. Claire Storey, Walport Academic Clinical Fellow, is a winner of Oral and Dental Research Trust funding for her research 'Investigation and quantification of key periodontal pathogens in diabetic patients'.

The group were pictured in James Bond mode at the BSDR conference dinner in Glasgow recently. 